\title{
Early changes in blood-based joint tissue destruction biomarkers are predictive of response to tocilizumab in the LITHE study
}

(1) CrossMark

\author{
Anne C. Bay-Jensen ${ }^{1 *}$, Adam Platt ${ }^{2,3}$, Anne Sofie Siebuhrr ${ }^{1}$, Claus Christiansen ${ }^{4}$, Inger Byrjalsen ${ }^{1,4}$ and Morten A. Karsdal ${ }^{1}$
}

\begin{abstract}
Background: Rheumatoid arthritis (RA) is characterized by gradual joint destruction. Tocilizumab (TCZ) significantly suppresses symptoms, however not all patients are protected from joint damage. We investigated whether early measurement of specific biomarkers could predict early joint protection response to tocilizumab.

Method: Serum biomarkers (CRPM, VICM, C1M, C2M, C3M (MMP-degraded CRP, vimentin type I, II and III collagen), CTX-I/OC (bone turnover), and CRP) were measured in 740 RA patients (the LITHE study) treated with Placebo, or 4 or $8 \mathrm{mg} / \mathrm{kg}$ TCZ. Early responders were those with $\geq 20 \%$ improvement in SJC or TJC by week 16. The biomarkers' predictability of response was investigated by AUROC and classification regression tree analysis.

Results: The best biomarker predictability for identification of TCZ responders were; baseline CTX-1/OC (AUC 0.66, $p=0.0005$ ) and changes in C1M (AUC 0.67, $p=0.0072)$, C2M (AUC 0.72, $p=0.0002), C 3 M(A \cup C 0.63, p=0.018$ ) and the combination of biomarkers (AUC 0.81, $\mathrm{p}=0.0025)$. Patients with high bone turnover $(\mathrm{CTX}-\mathrm{I} / \mathrm{OC}$ ) and low C2M were 6.8-fold ( $p=0.003)$ more likely to have an early response to TCZ.

Conclusion: This enhanced pharmacodynamic (PD) response enabled identification of early responders with a superior TCZ clinical benefit. This biomarker model may assist in the identification of TCZ responsive RA patients and thus potentially benefit individual patients.
\end{abstract}

Trial registration: Clinicaltrials.gov: NCT00106535. JAN 2005

Keywords: Tocilizumab, Rheumatoid arthritis, Biomarkers, Prediction of response

\section{Background}

Rheumatoid arthritis (RA) is a chronic autoimmune disease that is characterized by poly-articular inflammation manifested as swollen and tender joints, and by pain and joint deterioration resulting in progressive joint damage, impaired function, and disability $[1,2]$. One major challenge in the treatment of RA is selecting the right treatment at the right dose for the individual patient, thereby providing an optimal balance between benefit, safety and cost of treatment [3]. The RA population is heterogeneous and patients do not exhibit a linear progression of disease; thus, there is need for effective and non-invasive ways to monitor disease activity and progression in

\footnotetext{
*Correspondence: acbj@nordicbioscience.com

'Biomarkers and Research, Nordic Bioscience, Herlev Hovedgade 207, 2730 Herlev, Denmark

Full list of author information is available at the end of the article
}

individual patients. As a lack of predictive biomarkers limits the implementation of personalized health care (PHC), it is therefore important to identify robust biomarkers that are predictive of response [3].

Tocilizumab (TCZ) is a humanized anti-IL-6 receptor (IL-6R) monoclonal antibody. The effects of TCZ on joint tissue biomarkers measured in blood have been examined in several RA clinical studies, including LITHE [4] and RADIATE [5]. Previous studies have shown that 4 and $8 \mathrm{mg} / \mathrm{kg}$ TCZ suppress tissue turnover to a different extent [4], corresponding with the markedly different early response rate (i.e., American College of Rheumatology (ACR) 20 outcomes, 50 vs. $30 \%$ [6]. However the level of structural protection (change in Genant-modified total Sharp score) was comparable [7]. This indicates that there is heterogeneity of response within each dose group and 
that some patients will experience improvements only in disease activity but not in structural protection.

RA is affected by a persistent burden of proinflammatory cytokines, such as interleukins (e.g., IL-1, IL-6, and IL-17) and tumour necrosis factor alpha (TNF $\alpha$ ), which drives disease progression and activity. This leads to activation of several signalling cascades such as janus kinases (JAK), spleen tyrosine kinase (SYK) and mitogenactivated protein (MAP) kinase pathways, ultimately resulting in the secretion of proteolytical enzymes, such as matrix metalloproteinases (MMPs), which are the main mediators of tissue destruction [8]. Whereas the upstream inflammatory cytokines are fast modulating and short lived factors, the MMPs are often long-lived and can exert their action over an extended time period. The result is a longitudinal release of tissue destruction protein fragments that are discharged into the circulation and can be measured as direct assessments of joint destruction and protection in response to treatment [9]. MMP-derived fragments of type I, type II and type III collagen are the main collagens of joint extracellular matrix. Such fragments can be measured by assay as C1M [10], C2M and C3M [11]. Previous findings have shown that such types of biomarker are prognostic for structural disease progression and markers of efficacy in RA and other joint diseases [10-13]. Another biomarker is CRPM, which is a degradation fragment of $\mathrm{C}$-reactive protein (CRP). The main difference between CRPM and standard CRP is that CRPM is released from the inflammatory tissue as a marker of chronic inflammation, whereas CRP is released from the liver as an acute reactant [14].

Type I collagen is also the most abundant protein in bone [15], and its degradation by cathepsin $\mathrm{K}$ leads to the release of the C-terminal telopeptide of type I collagen (CTX-I) [16, 17]. Increased CTX-I levels are associated with elevated levels of IL-6 in postmenopausal women [18-20-21], and IL-6 alone activates osteoclast and augments bone resorption. CTX-I can be measured in both urine and serum and, decreases rapidly in response to anti-resorptive treatment in osteoporosis (OP) $[19,21,22-26]$. Bone formation can be assessed by measurement of osteocalcin [23]. As bone turnover is a delicate balance between bone resorption and bone formation, it may be more physiologically relevant to investigate the balance between these biomarkers, rather than assessing the markers separately. Bone formation is increased in postmenopausal women, which could suggest that bone health and volume are increased. However, as bone resorption increases at a greater rate than bone formation, there is a net bone loss [24]. Thus, investigating the balance between bone resorption and bone formation, eliminates issues of high and low turnover patients, who may possess similar bone balance, albeit at different bone turnover levels. Karsdal et al. [5] indicated that the bone turnover rather than the formation or degradation alone may be important for the response to TCZ.

As the effective treatment of RA also requires biomarkers that are predictive of therapeutic response, the aim of the study was to investigate whether measurement of selected blood-based tissue destruction biomarkers, assessed in RA patients at baseline or at an early time point post-treatment with TCZ, could be applied as diagnostic tools for selecting patients with a higher likelihood of response to treatment.

\section{Methods}

\section{Study design and serum samples}

The LITHE study has previously been described by Kremer et al., Smolen et al. and Bay-Jensen et al. [7,11,25] (clinicalTrials.gov identifier: NCT00106535). Briefly, the study is a 2-year phase III, multicentre, randomized, three-arm, placebo-controlled, parallel group trial in patients with moderate to severely active RA, who had inadequate responses to methotrexate (MTX). Patients were randomized 1:1:1 to one of three treatment groups: $4 \mathrm{mg} / \mathrm{kg}$ or $8 \mathrm{mg} / \mathrm{kg} \mathrm{TCZ}$, or placebo (PBO) in combination with a stable dosage of MTX (10-25 mg/week). TCZ and $\mathrm{PBO}$ were given intravenously every 4 weeks. Patients who failed to respond to treatment during the study, ie., they experienced $<20 \%$ improvement from baseline in the swollen joint count (SJC) and tender joint count (TJC) at week 16 or later, could receive blinded rescue therapy in a stepwise fashion between weeks 16 and 28 (see study description in paper by Kremer et al. [7,11,25]. The patients receiving rescue treatment after week 16 were described as early non-responders in this sub-analysis, whereas the patients who experienced at least a $20 \%$ improvement from baseline in SJC and TJC were described as early responders. Table 1 provide a short summary of the patient characteristics.

The study was approved by the ethics committee at each participating institution (the list can be found at https://clinicaltrials.gov/ct2/show/NCT00106535/) and was conducted according to the principles of Good Clinical Practice and according to the Declaration of Helsinki. The sub-analysis of this study was done on anonymized data, and the statistical analysis plan was approved by the projects teams at Nordic Bioscience and Hoffmann-La Roche. All patients provided written informed consent allowing for retrospective analysis of the blood samples for assessment of biomarkers of joint tissue turnover. No steering committee was used for this study.

\section{Sample processing}

In the study protocol, the use of serum for prospective and retrospective exploratory biomarker analysis was included and scheduled to be collected from patients who 
Table 1 Study overview; patient demographics and disease characteristics

\begin{tabular}{|c|c|c|c|}
\hline \multicolumn{4}{|l|}{ Baseline patient description } \\
\hline & Number & Mean & SD \\
\hline \multicolumn{4}{|l|}{ Patient characteristics } \\
\hline Age, years, SD & 740 & 52.5 & 12.3 \\
\hline Body mass index, $\mathrm{kg} / \mathrm{m}^{2}$ & 732 & 27.9 & 6.5 \\
\hline Disease duration, years & 740 & 9.6 & 8.2 \\
\hline Health assessment questionnaire & 676 & 1.5 & 0.6 \\
\hline Pain, $100 \mathrm{~mm}$ visual analogue scale & 733 & 54 & 22 \\
\hline Disease activity score in 28 joints & 726 & 6.5 & 0.93 \\
\hline \multicolumn{4}{|l|}{ Biomarker measures } \\
\hline C-reactive protein, $\mathrm{mg} / \mathrm{L}$ & 740 & 2.10 & 2.48 \\
\hline $\mathrm{C} 1 \mathrm{M}, \mathrm{nmol} / \mathrm{L}$ & 585 & 109 & 72 \\
\hline $\mathrm{C} 2 \mathrm{M}, \mathrm{nmol} / \mathrm{L}$ & 626 & 0.553 & 0.193 \\
\hline $\mathrm{C} 3 \mathrm{M}, \mathrm{nmol} / \mathrm{L}$ & 599 & 43.2 & 22.6 \\
\hline CRPM, nmol/L & 599 & 17.1 & 8.39 \\
\hline Matrix metalloproteinase $3, \mathrm{ng} / \mathrm{mL}$ & 676 & 54.3 & 60.5 \\
\hline Osteocalcin, nmol/L & 671 & 21.7 & 13.6 \\
\hline CTX-I, nmol/L & 671 & 0.413 & 0.201 \\
\hline CTX-I/OC ratio & 671 & 0.023 & 0.0136 \\
\hline
\end{tabular}

CIM, C2M, C3M matrix metalloproteinase-derived fragments of type I, type II and type III collagen, CRPM degradation fragment of C-reactive protein, CTX Cterminal telopeptide of type I collagen

provided informed written consent. The blood was collected in the morning after an overnight fast for $>8$ hours, at baseline, and weeks 4 and 16. All samples were aliquoted and stored frozen at a temperature below $-70{ }^{\circ} \mathrm{C}$ until assayed.

The biomarkers were measured at three different sites using different aliquots. CRP was measured by the different central laboratories associated with the study sites. CRP was measured in all patients in the biomarker substudy ( $\mathrm{n}=740)$. MMP3, osteocalcin (OC), CTX-I and C2M were measured by Synarc laboratory in Lyon France. Only 676 samples of the 740 originally included were available for measurement from the second aliquot and the volume was not sufficient to measure all biomarkers (e.g., $\mathrm{n}=626$ for measurement of C2M). C1M, C3M and CRPM were measured by Nordic Bioscience Laboratory in Roedovre, Denmark. Only 599 samples of the 740 originally included were available for measurement in the third aliquot and the volume was not sufficient to measure all biomarkers (e.g., $\mathrm{n}=585$ for measurement of $\mathrm{C} 1 \mathrm{M})$.

\section{Biochemical marker assays}

Serum levels of C1M [26], C2M [27], C3M [28] and CRPM [14] were measured, blinded to patient identity, by manual competitive ELISA. Briefly, for C1M and C2M, which measure MMP-degraded type I and II collagen fragments, respectively, Biotin-K-GSPGKDGVRG or biotin-KPPGRDGAAG (American peptide, Sunnyvale, CA, USA) were coated onto the streptavidin-pre-coated 96-well plate (Roche Diagnostics, Mannheim, Germany) and left for 30 minutes at $20{ }^{\circ} \mathrm{C}$. After washing (PBS $+10 \%$ tween 20), the calibrators, controls and undiluted serum samples were added, followed by peroxidase-conjugated monoclonal antibody NB104-4D3 or NB44-3C1, and incubated at $4{ }^{\circ} \mathrm{C}$ overnight. The sample-antibody mix was washed off the well plate and peroxidase reaction was visualized by 3,3',5,5' -tetramethylbenzidine (TMB, KemEn-tec, Taestrup, Denmark) at $20{ }^{\circ} \mathrm{C}$ and stopped with sulphuric acid after 15 minutes. For C3M, which measures the MMP-derived type III collagen neo-epitope, 96-well streptavidin-coated plates were coated with $0.4 \mathrm{ng} / \mathrm{mL}$ of KNGETGPQGP-biotin and left for 30 minutes at $20{ }^{\circ} \mathrm{C}$. After washing, calibrators, controls and serum samples (diluted 1:1 in incubation buffer) were added, followed by peroxidase-conjugated antibody NB51-G12. The sampleantibody mix was incubated at $20{ }^{\circ} \mathrm{C}$ for 60 minutes. TMB was added after washing of the plates and incubated at $20{ }^{\circ} \mathrm{C}$ and stopped with sulphuric acid after 15 minutes. CRPM measurement followed the same procedure as C3M, however, applying a different peroxidase-conjugated antibody (NB94-1A7) and coater (KAFVFPKESDK-biotin). After sample/calibrator incubation, the wells were washed and incubated with $100 \mu \mathrm{L}$ of TMB at $20^{\circ} \mathrm{C}$ for 15 minutes, followed by the addition of $100 \mu \mathrm{L}$ stop solution (sulphuric acid) in each well. The colorimetric reaction was measured at $450 \mathrm{~nm}$ with reference at $650 \mathrm{~nm}$ using the Softmax $\mathrm{Pro}^{\circ}$, version 5 software (Molecular Devices, Sunnyvale, CA, USA). The intra- and inter-assay coefficient of variation $(\mathrm{CV})$ was $<8 \%$ and $<10 \%$, respectively, for all assays described above.

Serum total MMP-3 was measured by a two-site ELISA using two polyclonal antibodies raised against human MMP-3 (Quantikine ${ }^{\circ}, \mathrm{R} \& D$ systems, Abingdon, UK). The intra- and inter-assay CV was $<10 \%$. Serum OC and CTX-I were measured by an automated multiplex assay (IMPACT bone chip, Roche Diagnostics, Mannheim, Germany) using the same antibodies as those employed in the corresponding single marker assays (Elecsys, Roche Diagnostics, Mannheim, Germany) [29].

\section{Statistical analyses}

No imputation was made on missing values, however, all data points were included resulting in different numbers of values being included in different analyses. Missing data points were observed for most variables, including clinical, demographic and biomarker parameters.

Summary statistics of general demographics, baseline RA characteristics, and baseline ACR criteria demographics (Table 1) included the number of patients and the mean and standard deviation. Changes in clinical 
scores and biomarkers from baseline to 4 weeks were investigated by the Wilcoxon paired rank sum test. The primary analysis (Figs. 1 and 2) was based on the mean percentage $(+/$ - standard error of the mean (SEM)) relative to the baseline measurement of the biochemical markers.

The area under the curve (AUC) for the separation by the biomarkers between early responders and nonresponders was tested by receiver-operator characteristic (ROC) curve analysis (Table 2). For markers with significant and consistent associations in the primary analysis, further associations between change in biomarker at baseline and week 4 were investigated using a dichotomous approach, either logistic regression or classification and regression analysis, in which patients were categorized according to designation of high and low levels, and responders and non-responders, using unpruned data. Odds ratios were calculated using these cutoff values.

All statistical analyses were performed using MedCalc version 12.3.0. Graphing was performed using Prism Graphpad version 5.03.

\section{Results}

Changes in biomarkers from baseline to 4 weeks in early responders and non-responders

The 8 - $\mathrm{mg} / \mathrm{kg}$-dose group was investigated first, as this dose had the greatest effect on biomarkers. Eight serum biomarkers were quantified and the percentage change from baseline was investigated by comparing early nonresponders to early responders. There was no difference in the suppression in CRP between early responders and
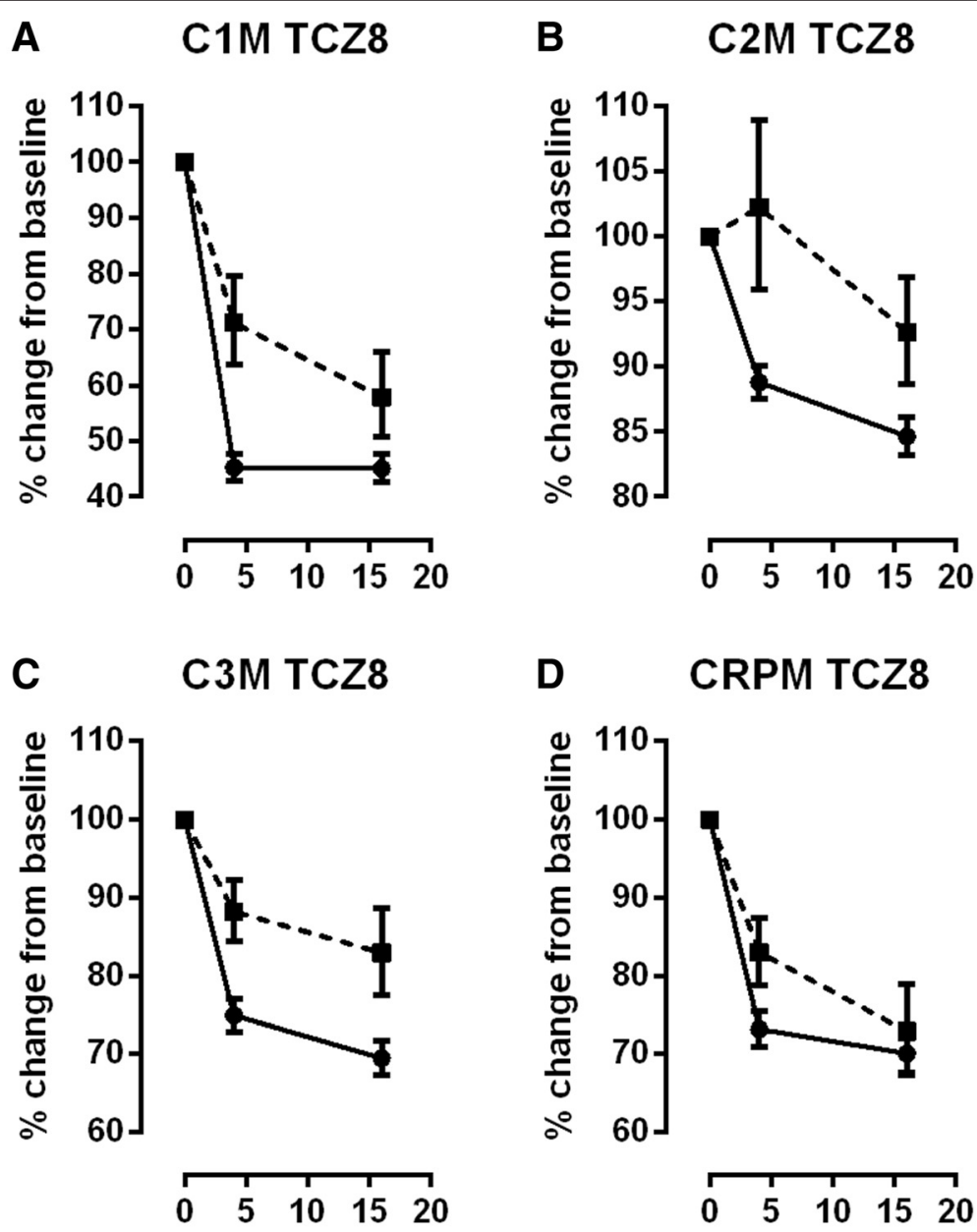

\section{- Early non-responders}

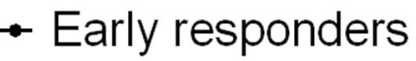

Fig. 1 Level of biomarker suppression in early responders (solid line) and non-responders (dotted line) in response to 8 mg/kg tocilizumab (TCZ). Levels of (a) matrix metalloproteinase (MMP)-mediated type I collagen fragments (CTM), (b) MMP-mediated type II collagen degradation fragments $(C 2 M)$, (c) MMP-mediated type III collagen degradation fragments (C3M), and (d) total MMP-mediated C-reactive protein degradation fragments (CRPM). Data are percentage change from baseline and mean \pm standard error. Absolute values can be found in Additional file 1: Table S1 

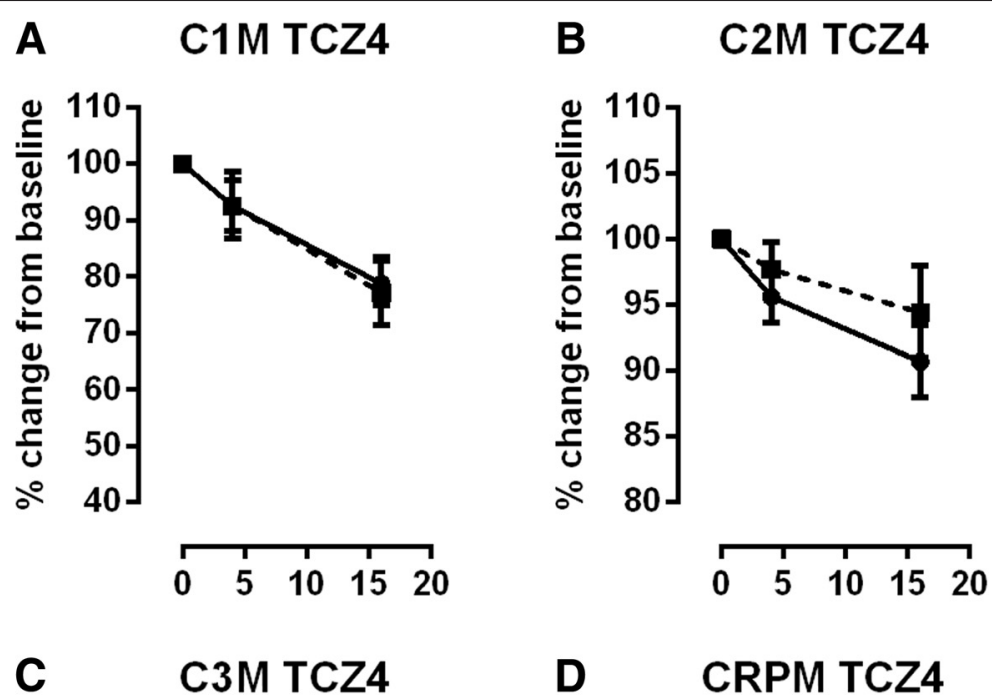

D $\quad$ CRPM TCZ4
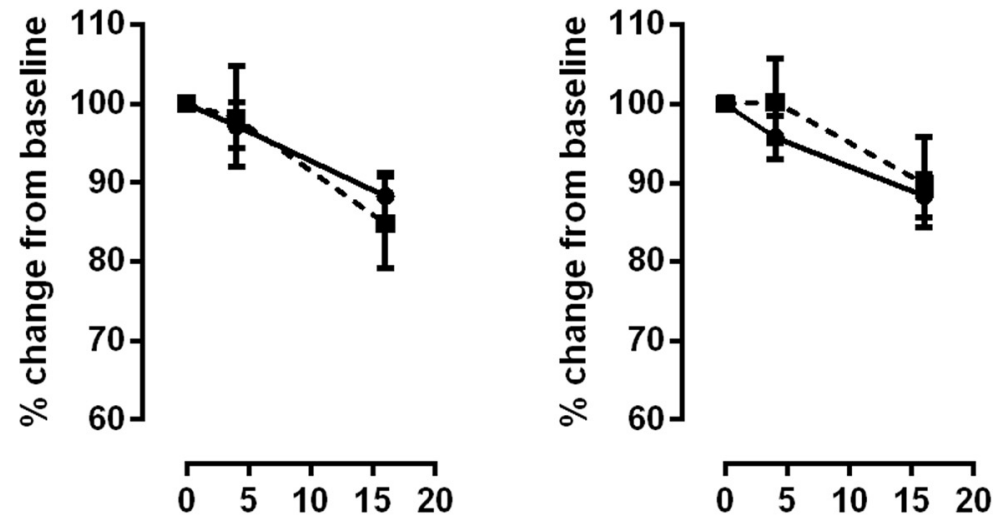

\section{-. Early non-responders $\rightarrow$ Early responders}

Fig. 2 Level of biomarker suppression in early responders (solid line) and non-responders (dotted line) in response to 4 mg/kg tocilizumab (TCZ). Levels of (a) matrix metalloproteinase (MMP)-mediated type I collagen fragments (C1M), (b) MMP-mediated type II collagen degradation fragments $(C 2 M)$, (c) MMP-mediated type III collagen degradation fragments (C3M), and (d) total MMP-mediated C-reactive protein degradation fragments (CRPM). Data are percentage change from baseline and mean \pm standard error. Absolute values can be found in Additional file 1: Table S2

non-responders; all patients treated with $8 \mathrm{mg} / \mathrm{kg} \mathrm{TCZ}$ reached normalized levels of CRP (Additional file 1: Figure S1). In contrast, levels of serum C1M, C2M and $\mathrm{C} 2 \mathrm{M}$ were already significantly inhibited after 4 weeks in early responders as compared to non-responders $(p<0.01)$ (Fig. 1a, b and c). Suppression of serum CRPM was slower in early non-responders $(p<0.05)$, but reached the level of the responders at week 16 (Fig. 1d). Suppression of serum MMP3 did not differ at week 4, but there was a trend towards separation between the two groups at week 16 (Additional file 1: Figure S1). There were no significant differences between responders and non-responders when looking at the ratio between CTX-I and OC (Additional file 1: Figure S1).

Table 2 Number of patients from each each treatment or early responder groups classified as Mode of action responders or nonresponders.

\begin{tabular}{lll}
\hline & Mode of action, non-responders $(\mathrm{n}=353)$ & Mode of action, responders $(\mathrm{n}=178)$ \\
\hline Number on tocilizumab $8 \mathrm{mg} / \mathrm{kg}(\%), \mathrm{n}=175$ & $37(7 \%)$ & $138(26 \%)$ \\
Number on tocilizumab $4 \mathrm{mg} / \mathrm{kg}(\%), \mathrm{n}=175$ & $146(27 \%)$ & $29(5 \%)$ \\
Number on placebo $(\%), \mathrm{n}=181$ & $170(32 \%)$ & $11(2 \%)$ \\
Number of early responders & $228(43 \%)$ & $144(27 \%)$ \\
Number of early non-responders & $125(24 \%)$ & $34(6 \%)$ \\
\hline
\end{tabular}


The percentage change from baseline for eight serum biomarkers was investigated for early non-responders and responders (Fig. 2). The suppression of biomarkers in the responder group was less significant in the $4 \mathrm{mg} / \mathrm{kg}$ than the $8 \mathrm{mg} / \mathrm{kg}$ treatment group (Fig. 1 vs. Fig. 2). None of the differences observed between responders and nonresponders with the $8 \mathrm{mg} / \mathrm{kg}$ dose were replicated in the $4 \mathrm{mg} / \mathrm{kg}$ group. There was no significant change in the biomarker levels in the placebo group (data not shown).

\section{Identification of a mode-of-action patient subset}

TCZ is a direct modulator of CRP levels as TCZ inhibits the release of CRP from the liver. This is part of the mode of action (MoA) of TCZ. Patients were separated into MoA responders and non-responders: 353 of 529 patients had $<75 \%$ reduction in CRP (Table 2). A total of 178 patients had $>75 \%$ reduction in CRP, when 138 were treated with $8 \mathrm{mg} / \mathrm{kg}$ TCZ, 29 were treated with $4 \mathrm{mg} / \mathrm{kg}$ TCZ and 11 were treated with PBO. In the MoA responder group 228 of the 353 were early nonresponders.

\section{Biomarker stratification of early responders and non-responders}

The MoA responder-patient subset was used to investigate which biomarkers provided the best discriminative power, by univariate testing followed by multivariate testing. None of the biomarkers at baseline distinguished early responders from non-responders except for baseline CTX-I/OC, reflecting bone turnover, which significantly separated the two groups (AUC 0.66, $p=0.0005$ (Table 3)).

Four-week change in serum C1M, C2M and C3M significantly separated responders from non-responders with an AUC of $0.67(p=0.0075), 0.72(p=0.0002)$ and $0.63(p=0.018)$ (Table 3$)$. The absolute mean values of each of the biomarkers at baseline and at follow up can be found in Additional file 1: Table S1.
Combining the biomarkers by logistic regression provided an AUC of $0.79(p=0.0003)$ (Table 4). This became marginally better by adding age, gender, body mass index (BMI) and disease duration into the regression model providing an AUC of $0.81(p=0.0025)$. The best minimum model included baseline CTX-I/OC, change in $\mathrm{C} 2 \mathrm{M}$ and age (AUC 0.80, $p=0.0001$ ) (Table 4).

\section{Classification and regression tree analysis}

The combination of biomarkers was further investigated as a predictive tool by testing them using classification and regression tree analysis, including the significant biomarkers from Table 3. In the MoA patient subset, a high CTX-I/OC ratio at baseline $(>0.024)$ identified 47 of the 135 early responders (purity $96 \%$ ): only 2 of 30 non-responders were falsely selected (Fig. 3a). Of the remaining 116 patients with a low CTX-I/ratio, 55 had change in C2M $<11 \%$ (89\% of baseline). This node identified 49 of the early nonresponders with purity of $89 \%$ (Fig. 3a). Overall CART analysis provided an odds ratio of $6.8(p<0.0001)$.

\section{Discussion}

All RA patients do not benefit to the same extent from the numerous RA therapies available, suggesting stratification of patients is required [3,30]. Although still vigorously debated, preliminary evidence suggests that PHC for RA may be achievable [3]. In the current study, we showed that in addition to the commonly used biomarkers, CRP and MMP3, the protein fingerprint biomarkers C1M, C2M, C3M and CRPM were significantly suppressed at weeks 4 and 16 after treatment with TCZ, in a dose-dependent manner with $8 \mathrm{mg} / \mathrm{kg}$ significantly superior to the $4 \mathrm{mg} / \mathrm{kg}$ dose. In alignment with previous findings $[10,11]$, the patterns of suppression of these markers were markedly different between the two doses and between responders and non-responders. In the current study, we investigated the end product of tissue destruction by measuring the collagen fragments $\mathrm{C} 1 \mathrm{M}, \mathrm{C} 2 \mathrm{M}$ and C3M. Clearly these tissue destruction

Table 3 Area under the receiver operating characteristic curve of individual biomarker levels at baseline and change from baseline to 4 weeks for prediction of early response (week 16)

\begin{tabular}{|c|c|c|c|c|c|c|c|c|}
\hline & \multicolumn{4}{|c|}{ Baseline biomarkers } & \multicolumn{4}{|c|}{ Change from baseline to 4 weeks } \\
\hline & $\overline{A U C}$ & Standard error & $95 \% \mathrm{Cl}^{\mathrm{b}}$ & $P$ value & $\overline{A U C}$ & Standard error & $95 \% \mathrm{Cl}$ & $P$ value \\
\hline C-reactive protein & 0.537 & 0.0611 & 0.461 to 0.611 & Ns & 0.643 & 0.0577 & 0.555 to 0.724 & Ns \\
\hline $\mathrm{C} 1 \mathrm{M}$ & 0.506 & 0.0599 & 0.431 to 0.581 & Ns & 0.674 & 0.0599 & 0.587 to 0.752 & 0.0072 \\
\hline $\mathrm{C} 2 \mathrm{M}$ & 0.526 & 0.0580 & 0.450 to 0.600 & Ns & 0.723 & 0.0551 & 0.639 to 0.797 & 0.0002 \\
\hline C $3 M$ & 0.557 & 0.0541 & 0.481 to 0.631 & Ns & 0.630 & 0.0581 & 0.542 to 0.711 & 0.018 \\
\hline CRPM & 0.531 & 0.0567 & 0.455 to 0.605 & Ns & 0.568 & 0.0650 & 0.480 to 0.654 & ns \\
\hline MMP3 & 0.622 & 0.0576 & 0.548 to 0.693 & Ns & 0.627 & 0.0623 & 0.540 to 0.709 & ns \\
\hline CTX-I/OC & 0.655 & 0.0493 & 0.581 to 0.724 & 0.0005 & 0.553 & 0.0660 & 0.465 to 0.639 & ns \\
\hline
\end{tabular}

*P value adjusted for age, gender and disease duration. AUC area under the curve, CIM, C2M, and C3M matrix metalloproteinase-derived fragments of type I, type II and type III collagen, MMP matrix metalloproteinase, CRPM degradation fragment of C-reactive protein, CTX-I/OC C-terminal telopeptide of type I collagen/osteocalcin 
Table 4 Logistic regression model for accessing the area under the curve (AUC) for different combinations

\begin{tabular}{llllllll}
\hline & & & & \multicolumn{3}{l}{ Including age, BMl, gender and disease duration } \\
\cline { 5 - 8 } Variables & AUC & $95 \% \mathrm{Cl}$ & $P$ value & AUC & $95 \% \mathrm{Cl}$ & $P$ value* \\
\hline Baseline CTX-I/OC and delta 4 weeks C1M, C2M, C3M ( $\mathrm{n}=124)$ & 0.79 & 0.71 to 0.86 & 0.0003 & 0.81 & 0.72 to 0.87 & 0.0025 \\
Baseline CTX-I/OC and delta 4 weeks C2M (and age) & 0.78 & 0.69 to 0.85 & $<0.0001$ & 0.80 & 0.71 to 0.86 & 0.0001 \\
\hline
\end{tabular}

The first row show results of applying an enter model, where all variable were added, whereas the second row provide a backward model where all non-significant variables were excluded $(n=124)$. BMI body mass index, CTX-I/OC C-terminal telopeptide of type I collagen/osteocalcin, CIM, C2M, and C3M matrix metalloproteinase-derived fragments of type I, type II and type III collagen. * P value for the full logistic model.

markers provided a dynamic dose and time resolution of the pharmacodynamic (PD) effects. C1M, C2M and C3M are all significantly suppressed by $8 \mathrm{mg} / \mathrm{kg} \mathrm{TCZ}$, and not by $4 \mathrm{mg} / \mathrm{kg}$, compared to the placebo group [11].

None of the tissue and inflammatory biomarkers measured at baseline were predictive of response to TCZ, with the exception of bone turnover ratio, which was significantly higher for early responders than non-responders. This suggests that TCZ has a superior effect in patients with destabilized bone turnover, and levels of CTX-I/OC may be used as a selection tool for patients who may benefit from TCZ. Importantly this is not the case for $4 \mathrm{mg} / \mathrm{kg} \mathrm{TCZ}$, with which baseline levels of C1M, C3M and CRPM are associated with response [11]. The four biomarkers of joint tissue matrix turnover, C1M, C2M, C3M and CTX-I/OC, measured at either baseline or at 4 weeks post treatment, were predictive of early clinical response. Thus, RA patients, subject to IL6-R antagonism, can potentially be stratified into responders and non-responders as early as 4 weeks post treatment.
While it is difficult to interpret the serum levels of pro-inflammatory cytokines and acute-phase reactants, because of their rather acute signalling pathways, it may be the total burden of cytokines rather than one individual cytokine that is the final driver of disease progression. Measuring end products of tissue destruction, which are the downstream effect of the inflammatory signals, may enable more exact monitoring of tissue turnover [31]. As many enzymes degrade proteins at hot-spots, this may be considered as a convergence of signalling pathways leading to tissue turnover and remodelling - the final part of tissue destruction. Tissue destruction, therefore, may be measured through specific circulating tissue protein fragments generated by upregulated collagenolytic enzymes [9, 32], the unique end result of specific pathological events. As an example, the major extracellular matrix (ECM) proteins of connective tissue of the joints are type I, II and III collagen [33]. The MMP-mediated degradation of these proteins

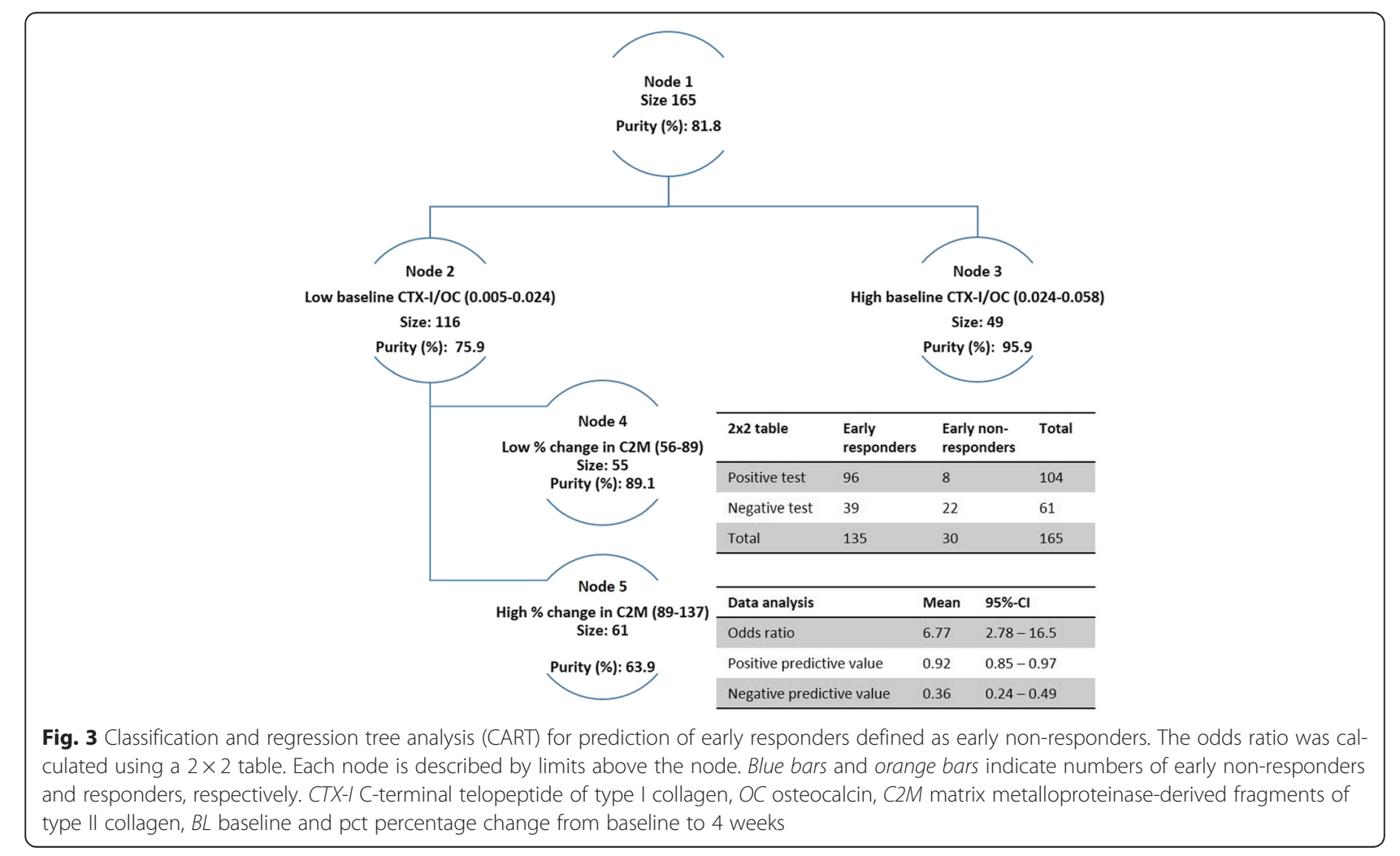


results in specific biomarkers, $\mathrm{C} 1 \mathrm{M}, \mathrm{C} 2 \mathrm{M}$ and $\mathrm{C} 3 \mathrm{M}$, respectively $[5,10,26,28,34]$. This may provide a more robust and less variable biomarker approach for use as a diagnostic or prognostic tool.

While we consider it is an overall strength of the study that it was conducted in the context of a well-controlled phase III clinical trial, this may also be a weakness. The study population represents a subset of RA patients screened and selected from the general RA population. As such the predictive models described may apply to RA patients with similar clinical characteristics to those used for model training in this study, requiring the model to be validated in independent populations or trials. Another limitation of the study is the relatively small sample size for generation of a predictive model, which may lead to some model over-fitting and thus, potential overestimation of effect size.

\section{Conclusions}

We have demonstrated the identification of TCZ responders through analysis of simple combinations of protein degradation markers. There was a significant difference in response prediction between the 4 and $8 \mathrm{mg} / \mathrm{kg}$ doses. MMP-mediated tissue destruction was strongly attenuated by TCZ treatment, which suggests that over-fitting of the dataset is less likely.

\section{Additional file}

\section{Additional file 1 Supplementary data for Re: Arthritis Research \& Therapy: 1228461238172039 Title: Early changes in blood-based joint tissue destruction biomarkers are predictive of response to tocilizumab in the LITHE study. (PPTX $186 \mathrm{~kb}$ )}

\section{Abbreviations \\ ACR: American College of Rheumatology; AUC: area under the curve; CART Classification and regression tree CIM, C2M, C3M: matrix metalloproteinase- derived fragments of type I, type II and type III collagen; CRP: C-reactive protein; CRPM: degradation fragment of CRP; CTX-I: C-terminal telopeptide of type I collagen; ELISA: enzyme-linked immunosorbent assay; IL: interleukin; JAK: janus kinase; MAP: mitogen-activated protein; MMP: matrix metalloproteinase; MoA: mode of action; MTX: methotrexate; OC: osteocalcin; OP: osteoporosis; PBO: placebo; PBS: phosphate-buffered saline; PD: pharmacodynamics; PHC: personalized health care; RA: rheumatoid arthritis; ROC: receiver-operator curve; SYK: spleen tyrosine kinase; TCZ: tocilizumab; TMB: tetramethylbenzidine; wk: week.}

\section{Competing interests}

$A C B J, A S O, I B$ and MAK are full-time employees at Nordic Bioscience, a privately owned biotech company involved in the development of biomarkers. CC, ACBJ and MAK are shareholders of Nordic Bioscience. AP was a full-time employee of Roche Product at the time of data analysis, and currently is a full-time employee of AstraZeneca. None of the authors declare any other conflict of interest.

\section{Authors' contributions}

ACBJ conducted the analysis of the data and wrote the first draft of the paper. AP collected the clinical data. MAK designed the analysis of the study, including the choice of biomarkers and the construction of the statistical analysis plan. ASO did the biomarker assessments. IB did the multivariate statistical analyses. All authors participated in the discussion of the results. All authors read and approved the manuscript.

\section{Acknowledgements}

We with like to acknowledge the technical staff at Nordic Bioscience for laboratory support, and the Danish Research Foundation for general support of our research especially Sabine Hoielt and Sedi Tavallaee. Furthermore we would like to thank Dr. Thierry Sornasse and colleagues at Roche Products Ltd. for providing the study samples. Also we would like to thank the participating patients for providing the blood samples. We would also like to acknowledge the contribution of our friends at Synarc laboratories in Lyon, France, for providing the C2M measurements. The study analysis was funded by the Danish Research foundation.

\section{Author details}

${ }^{1}$ Biomarkers and Research, Nordic Bioscience, Herlev Hovedgade 207, 2730 Herlev, Denmark. ${ }^{2}$ Roche Products Ltd., Welwyn Garden City, UK. ${ }^{3}$ Present Address: AstraZeneca UK Ltd., Cheshire, UK. ${ }^{4}$ Clinical Development, Nordic Bioscience, Herlev, Denmark.

Received: 13 May 2015 Accepted: 29 December 2015

Published online: 20 January 2016

\section{References}

1. Schett G, Hayer S, Zwerina J, Redlich K, Smolen JS. Mechanisms of Disease: the link between RANKL and arthritic bone disease. Nat Clin Pract Rheumatol. 2005;1(1):47-54.

2. Diarra D, Stolina M, Polzer K, Zwerina J, Ominsky MS, Dwyer D, et al. Dickkopf-1 is a master regulator of joint remodeling. Nat Med. 2007;13(2):156-63.

3. Karsdal MA, Bay-Jensen AC, Henriksen K, Christiansen C, Genant HK, Chamberlain C, et al. Rheumatoid arthritis - A case for Personalised Health Care? Arthritis Care Res (Hoboken). 2014;66(9):1273-80

4. Bay-Jensen AC, Platt A, Byrjalsen I, Vergnoud P, Christiansen C, Karsdal MA Effect of tocilizumab combined with methotrexate on circulating biomarkers of synovium, cartilage, and bone in the LITHE study. Semin Arthritis Rheum. 2014;43(4):470-8.

5. Karsdal MA, Schett G, Emery P, Harari O, Byrjalsen I, Kenwright A, et al. IL-6 Receptor Inhibition Positively Modulates Bone Balance in Rheumatoid Arthritis Patients with an Inadequate Response to Anti-Tumor Necrosis Factor Therapy: Biochemical Marker Analysis of Bone Metabolism in the Tocilizumab RADIATE Study (NCT00106522). Semin Arthritis Rheum. 2012;42(2):131-9.

6. Emery P, Keystone E, Tony HP, Cantagrel A, van Vollenhoven R, Sanchez A, et al. IL-6 receptor inhibition with tocilizumab improves treatment outcomes in patients with rheumatoid arthritis refractory to anti-tumour necrosis factor biologicals: results from a 24-week multicentre randomised placebo-controlled trial. Ann Rheum Dis. 2008;67(11):1516-23.

7. Smolen JS, Avila JC, Aletaha D. Tocilizumab inhibits progression of joint damage in rheumatoid arthritis irrespective of its anti-inflammatory effects: disassociation of the link between inflammation and destruction. Ann Rheum Dis. 2012;71(5):687-93.

8. Yazici Y, Regens AL. Promising new treatments for rheumatoid arthritis - the kinase inhibitors. Bull NYU Hosp Jt Dis. 2011;69(3):233-7.

9. Karsdal MA, Delvin E, Christiansen C. Protein fingerprints - relying on and understanding the information of serological protein measurements. Clin Biochem. 2011;44(16):1278-9.

10. Siebuhr AS, Bay-Jensen AC, Leeming DJ, Plat A, Byrjalsen I, Christiansen C, et al. Serological identification of fast progressors of structural damage with rheumatoid arthritis. Arthritis Res Ther. 2013;15(4):R86.

11. Bay-Jensen AC, Platt A, Byrjalsen I, Vergnoud P, Christiansen C, Karsdal MA. Effect of tocilizumab combined with methotrexate on circulating biomarkers of synovium, cartilage, and bone in the LITHE study. Semin Arthritis Rheum. 2014:43(4):470-8

12. Bay-Jensen AC, Karsdal MA, Vassiliadis E, Wichuk S, Marcher-Mikkelsen K, Lories $\mathrm{R}$, et al. Circulating citrullinated vimentin fragments reflect disease burden in ankylosing spondylitis and have prognostic capacity for radiographic progression. Arthritis Rheum. 2013;65(4):972-80.

13. Valdes AM, Meulenbelt I, Chassaing E, Arden NK, Bierma-Zeinstra S, Hart D, et al. Large scale meta-analysis of urinary C-terminal telopeptide, serum cartilage oligomeric protein and matrix metalloprotease degraded type ॥ collagen and their role in prevalence, incidence and progression of osteoarthritis. Osteoarthritis Cartilage. 2014;22(5):683-9.

14. Skjot-Arkil H, Schett G, Zhang C, Larsen DV, Wang Y, Zheng Q et al. Investigation of two novel biochemical markers of inflammation, matrix metalloproteinase and cathepsin generated fragments of C-reactive protein, in patients with ankylosing spondylitis. Clin Exp Rheumatol. 2012;30(3):371-9. 
15. Seeman E, Delmas PD. Bone quality-the material and structural basis of bone strength and fragility. N Engl J Med. 2006;354(21):2250-61.

16. Garnero P, Ferreras M, Karsdal MA, NicAmhlaoibh R, Risteli J, Borel O, et al. The type I collagen fragments ICTP and CTX reveal distinct enzymatic pathways of bone collagen degradation. J Bone Miner Res. 2003;18(5):859-67.

17. Sassi ML, Eriksen H, Risteli L, Niemi S, Mansell J, Gowen M, et al. Immunochemical characterization of assay for carboxyterminal telopeptide of human type I collagen: loss of antigenicity by treatment with cathepsin K. Bone. 2000;26(4):367-73.

18. Bonde M, Qvist P, Fledelius C, Riis BJ, Christiansen C. Applications of an enzyme immunoassay for a new marker of bone resorption (CrossLaps): follow-up on hormone replacement therapy and osteoporosis risk assessment. J Clin Endocrinol Metab. 1995;80(3):864-8.

19. Rosenquist C, Fledelius C, Christgau S, Pedersen BJ, Bonde M, Qvist P, et al. Serum CrossLaps One Step ELISA. First application of monoclonal antibodies for measurement in serum of bone-related degradation products from C-terminal telopeptides of type I collagen. Clin Chem. 1998;44(11):2281-9.

20. Recker R, Lappe J, Davies KM, Heaney R. Bone remodeling increases substantially in the years after menopause and remains increased in older osteoporosis patients. J Bone Miner Res. 2004;19(10):1628-33.

21. Leeming DJ, Alexandersen P, Karsdal MA, Qvist P, Schaller S, Tanko LB. An update on biomarkers of bone turnover and their utility in biomedical research and clinical practice. Eur J Clin Pharmacol. 2006;62(10):781-92.

22. Reginster JY, Henrotin Y, Christiansen C, Gamwell-Henriksen E, Bruyere, Collette J, et al. Bone resorption in post-menopausal women with normal and low BMD assessed with biochemical markers specific for telopeptide derived degradation products of collagen type I. Calcif Tissue Int. 2001;69(3):130-7.

23. Karsdal MA, Henriksen K, Leeming DJ, Mitchell P, Duffin K, Barascuk N, et al. Biochemical markers and the FDA Critical Path: how biomarkers may contribute to the understanding of pathophysiology and provide unique and necessary tools for drug development. Biomarkers. 2009;14(3):181-202.

24. Karsdal MA, Qvist P, Christiansen C, Tanko LB. Optimising antiresorptive therapies in postmenopausal women: why do we need to give due consideration to the degree of suppression? Drugs. 2006;66(15):1909-18.

25. Kremer JM, Blanco R, Brzosko M, Burgos-Vargas R, Halland AM, Vernon E, et al. Tocilizumab inhibits structural joint damage in rheumatoid arthritis patients with inadequate responses to methotrexate: results from the double-blind treatment phase of a randomized placebo-controlled trial of tocilizumab safety and prevention of structural joint damage at one year. Arthritis Rheum. 2011;63(3):609-21.

26. Leeming $D$, He $Y$, Veidal S, Nguyen $Q$, Larsen D, Koizumi M, et al. A novel marker for assessment of liver matrix remodeling: an enzyme-linked immunosorbent assay (ELISA) detecting a MMP generated type I collagen neo-epitope (C1M). Biomarkers. 2011;16(7):616-28.

27. Bay-Jensen AC, Leeming DJ, Kleyer A, Veidal SS, Schett G, Karsdal MA. Ankylosing spondylitis is characterized by an increased turnover of several different metalloproteinase-derived collagen species: a cross-sectional study. Rheumatol Int. 2012;32(11):3565-72

28. Barascuk N, Veidal SS, Larsen L, Larsen DV, Larsen MR, Wang J, et al. A novel assay for extracellular matrix remodeling associated with liver fibrosis: An enzyme-linked immunosorbent assay (ELISA) for a MMP-9 proteolytically revealed neo-epitope of type III collagen. Clin Biochem. 2010;43(10-11):899-904.

29. Claudon A, Vergnaud P, Valverde C, Mayr A, Klause U, Garnero P. New automated multiplex assay for bone turnover markers in osteoporosis. Clin Chem. 2008:54(9):1554-63.

30. Smolen JS, Aletaha D. Forget personalised medicine and focus on abating disease activity. Ann Rheum Dis. 2013;72(1):3-6.

31. Karsdal MA, Bay-Jensen AC, Leeming DJ, Henriksen K, Christiansen C. Quantification of "end products" of tissue destruction in inflammation may reflect convergence of cytokine and signaling pathways - implications for modern clinical chemistry. Biomarkers. 2013;18(5):375-8.

32. Karsdal MA, Henriksen K, Leeming DJ, Woodworth T, Vassiliadis E, Bay-Jensen AC. Novel combinations of Post-Translational Modification (PTM) neo-epitopes provide tissue-specific biochemical markers-are they the cause or the consequence of the disease? Clin Biochem. 2010;43(10-11):793-804.

33. Schuppan D, Ruehl M, Somasundaram R, Hahn EG. Matrix as a modulator of hepatic fibrogenesis. Semin Liver Dis. 2001;21(3):351-72.

34. Bay-Jensen AC, Liu Q, Byrjalsen I, Li Y, Wang J, Pedersen C, et al. Enzymelinked immunosorbent assay (ELISAs) for metalloproteinase derived type ॥ collagen neoepitope, CIIM-increased serum CIIM in subjects with severe radiographic osteoarthritis. Clin Biochem. 2011;44(5-6):423-9.

\section{Submit your next manuscript to BioMed Central and we will help you at every step:}

- We accept pre-submission inquiries

- Our selector tool helps you to find the most relevant journal

- We provide round the clock customer support

- Convenient online submission

- Thorough peer review

- Inclusion in PubMed and all major indexing services

- Maximum visibility for your research

Submit your manuscript at www.biomedcentral.com/submit 